\title{
A dynamic solution of the shear band propagation in submerged landslides
}

\section{Journal Article}

Author(s):

Puzrin, Alexander M.; Saurer, Erich; Germanovich, Leonid N.

Publication date:

2010

Permanent link:

https://doi.org/10.3929/ethz-b-000018115

Rights / license:

In Copyright - Non-Commercial Use Permitted

Originally published in:

Granular Matter 12(3), https://doi.org/10.1007/s10035-010-0177-8 


\title{
A dynamic solution of the shear band propagation in submerged landslides
}

\author{
Alexander M. Puzrin • Erich Saurer • \\ Leonid N. Germanovich
}

Received: 7 May 2009 / Published online: 3 April 2010

(C) Springer-Verlag 2010

\begin{abstract}
A failure mechanism of submarine landslides based on the phenomenon of shear band propagation has been investigated using the energy balance approach. Dynamic analysis includes inertia effects in the sliding layer and viscous resistance of the water, but ignores elastic and plastic wave propagation in the sliding layer. The resulting differential equation has been solved numerically. Analytical approximation of this numerical solution provides a convenient basis for the parametric and sensitivity studies. The solution allows assessing the velocity and acceleration of both the landslide and the shear band at the moment when the slide fails due to the limiting equilibrium (i.e., the initial post-failure velocity). The effects of the initial landslide velocity on the tsunami wave height are discussed and validated for a number of landslide examples.
\end{abstract}

Keywords Progressive and catastrophic failure .

Shear bands $\cdot$ Fracture mechanics $\cdot$ Landslides

\section{Introduction}

Understanding the mechanisms of tsunamis and their sources is a key task for the tsunami hazard assessment and mitigation. Recent devastating tsunami events, such as the

A. M. Puzrin · E. Saurer $(\bowtie)$

Institute for Geotechnical Engineering, ETH Zurich,

Wolfgang-Pauli-Strasse 49, 8093 Zurich, Switzerland

e-mail: erich.saurer@gmail.com

A. M. Puzrin

e-mail: alexander.puzrin@igt.baug.ethz.ch

L. N. Germanovich

Center for Applied Geomaterials Research, Georgia Institute

of Technology, Atlanta, USA

e-mail: leonid.germanovich@ce.gatech.edu
1998 Papua New Guinea tsunami and the event in 2004 in the Indian Ocean have aroused the public and scientific interest on an improved understanding of the triggering mechanisms and tsunami hazard assessment [1-4]. Although tsunamis often occur directly due to normal faulting of earth plates [5], it has been shown that submarine landslides, triggered by earthquakes, may also cause tsunami waves of a significant height. Overview on earthquake related triggering mechanisms of submarine and shoreline slope instabilities have been provided by several authors [6,7]. The authors distinguish between direct, such as acceleration- or liquefactioninduced sliding, and indirect triggering mechanisms, such as a delayed failure mechanism due to excess pore water pressure. The general tendency, however, is to assume that the landslide fails simultaneously along the entire sliding surface, which can be tens and $100 \mathrm{~km}$ long. This assumption is also behind the fact that numerical simulations of landslide induced tsunamis [8-10] tend to underestimate the tsunami wave height.

These limitations can be overcome, if the landslide failure is considered as a dynamic process, and not as a static limiting equilibrium event. Such an approach has been proposed by Puzrin and Germanovich [11,12], who suggested that an initial shear band emerges along a certain length of the potential failure surface. Within this shear band the shear strength drops due to the softening behavior of the material. Therefore, the soil above this weakened zone starts moving downwards, causing the shear band to propagate further along the potential failure surface. This produces an initial landslide velocity already before the slide reached the state of the global limiting equilibrium; i.e. the post failure stage.

Analysis of the mechanism is based on the energy balance approach of Palmer and Rice [13]: for the shear band to propagate, the energy surplus produced in the body by an incremental propagation of the shear band should exceed the 
energy required for this propagation. The main advantage of this model is that it allows distinguishing between progressive and catastrophic shear band propagation and treats the shear band as a true physical process and not just as a mathematical bifurcation problem [14]. Applications of the energy balance approach to the phenomenon of progressive shear band propagation in trapdoor- and shear blade tests on sand and silt have been investigated experimentally, analytically and numerically $[15,16]$. It seems that the energy balance approach provides a reasonable quantitative description of the shear band propagation phenomena in granular materials.

Analysis of the catastrophic shear band propagation in an infinite submerged slope built of normally consolidated clays has shown that relatively short initial failure zones are sufficient to cause a full-scale landslide [17]. An attempt to assess the initial landslide velocity at failure was also made [11], based on a quasi-static approach, neglecting the fundamental dynamic terms.

As will be shown below, this initial landslide velocity at failure plays an important role for the tsunami height assessment. Therefore, in spite of the complexity of the dynamic problem, it is worth exploring a possibility of producing a better estimate of this velocity. This paper briefly outlines an attempt to provide an improved approximation of the true dynamic solution. In this simplified approach, the stress distribution in the sliding layer is calculated using inertia terms and the viscous resistance of the water, but excluding propagation and reflection of elastic waves. In spite of this simplification, the energy balance includes the kinetic energy of the moving landslide and leads to a non-linear differential equation. While this equation can be solved numerically, for large lengths of the shear band the landslide velocity asymptotically approaches a closed form solution. This allows for estimation of the initial landslide velocity at the moment of failure. Some preliminary results of this work have been presented in [18]. This paper shows derivation of the landslide velocity equations and their solutions, parametric studies, validation of analytical approximations, and real landslide examples.

\section{Dynamic shear band propagation in an infinite slope}

\subsection{Geometry and soil behavior}

Consider an infinite slope inclined by angle $\alpha$ to the horizontal with a discontinuity zone at the depth $h$ parallel to the slope (Fig. 1). Starting from the initial weak zone of the length larger than critical $l>l_{c r}$ [17], a shear band propagates down the slope parallel to the surface. At the top of this zone, the soil fails in active failure with the active pressure $p_{a}$. It is assumed that the length of the discontinuity $l$ is

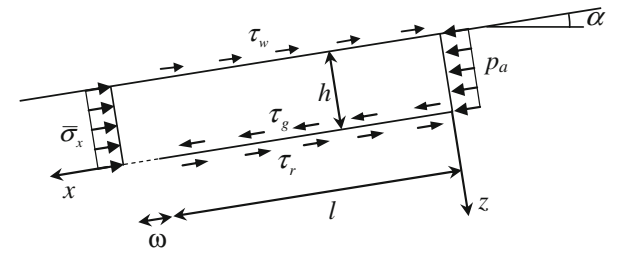

Fig. 1 Propagation of the shear band in an infinite slope. Parameters $\tau_{g} \tau_{r}$ are the same as defined in Ref. [13]

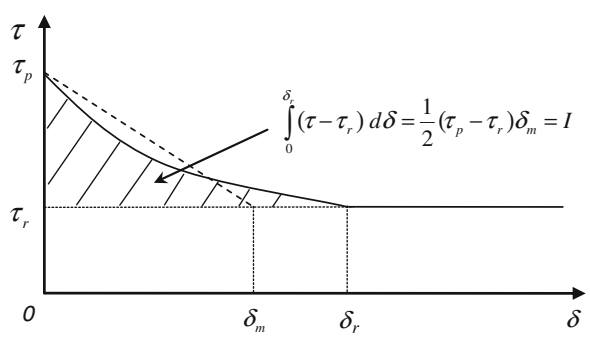

Fig. 2 Strain softening behaviour in the shear band process zone

sufficiently larger than its depth and the length of the process zone $\omega: l>h \gg \omega$. Within this small process zone, the shear resistance $\tau$ gradually drops from the peak $\tau_{p}$ to the residual value $\tau_{r}$, as a function of the relative displacement (Fig. 2). Within the rest of the shear band, the shear resistance is constant and equal to $\tau_{r}$. Outside the shear band and at the tip of the process zone, the shear resistance is equal to the peak value $\tau_{p}$. If the gravitational shear stress $\tau_{g}$ above the shear band exceeds the residual shear strength $\tau_{r}$, the soil above the shear band starts moving downwards, driving the shear band to propagate along the slope, until it comes to the surface and the slope fails (Fig. 1).

As the slope slides down, it mobilizes viscous resistance on the interface with water, which is proportional to the velocity of sliding $v$ :

$\tau_{w}=\mu v$

where $\mu$ is the coefficient of proportionality that scales with the viscosity of water, $\mu_{w}$. The main focus of this paper is the velocity of the shear band propagation and of the landslide velocity at the moment when the slide fails. Within the sliding layer $(l \times h \times 1$ in Fig. 1), the undrained character of the dynamic soil behavior requires total stress analysis. Although the total normal stress in the $x$-direction is a function of depth $z$, in this derivation, only the average value of this total stress across the sliding layer $\bar{\sigma}_{x}(x)$ is being considered. Before the shear band propagation, the average normal stress in the intact slope is $\bar{\sigma}_{x}=p_{0}$. As the shear band propagates, it starts growing. The soil behavior in the sliding layer is described by a one-dimensional elastic-plastic model with linear hardening, which in plastic loading is given by: $\bar{\sigma}_{x}=p_{0}+\varepsilon_{x} / E$, 


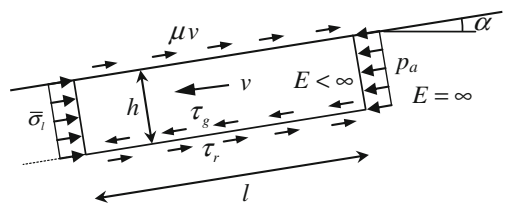

Fig. 3 Motion of the sliding layer $(E=\infty$ denotes domain which is assumed to be rigid)

where $E$ is the tangent elasto-plastic modulus of soil. Unloading is linear elastic governed by the unloading-reloading tangent modulus $E_{u r}$.

\subsection{Equation of motion}

The main simplification of the proposed model is in considering the sliding layer in the dynamic case, when all the points above the band are moving with the same velocity $v$ and, therefore, acceleration $\dot{v}$. Then, at each moment of time, the layer above the shear band can be considered as rigid body (Fig. 3) and from the equation of motion for this body the average normal stress above the tip of the shear band is obtained (Fig. 3):

$h \bar{\sigma}_{x}(l)=h \bar{\sigma}_{l}=\left(\tau_{g}-\tau_{r}\right) l+p_{a} h-\rho h l \dot{v}-\rho h \dot{l} v-\mu v l$

where $\rho$ is the density of the soil. The second term on the right side gives a contribution of the earth pressure at the upper boundary of the sliding layer (Fig. 1). While this boundary moves downhill with the sliding layer, the earth pressure is assumed to stay constant and equal to total active pressure $p_{a}$, which is the minimum total earth pressure achieved at large displacements. The fourth term reflects the fact that the mass of the moving body is increasing during the shear band propagation (the additional mass accelerates from zero velocity to $v$ ). The last term comes from the hydro-mechanical water resistance in Eq. 1.

\subsection{Energy balance approach}

The energy balance criterion for an incremental dynamic propagation of the shear band can be expressed in the following equation:

$\Delta W_{e}-\Delta W_{i}-\Delta D_{l}-\Delta D_{\mu}-\Delta K=\Delta D_{\omega}$

where $W_{e}$ is the external work made by gravitational forces on downhill movements of the layer; $W_{i}$ denotes the internal work of the normal stress acting parallel to the slope surface on the change of strains in the layer; $D_{l}$ is the dissipated energy due to plastic work along the shear band; $D_{\mu}$ is the dissipated energy at the soil-water interface; $K$ is the kinetic energy and $D_{\omega}$ is the plastic work required to overcome the peak shear resistance at the tip of the band, i.e. the softening in the process zone, see Eqs. (6)-(12). This equation is the same as suggested by Palmer and Rice [13] for the static case, except it includes the change $\Delta K$ of the kinetic energy and $\Delta D_{\mu}$ of the dissipated energy at the soil-water interface.

Incremental propagation of the shear band by $\Delta l$ over the time increment $\Delta t$ produces displacement of the entire sliding layer, proportional to the strain $\varepsilon_{l}$ in the portion of the sliding layer above $\Delta l$ :

$$
\Delta \delta=\varepsilon_{l} \Delta l
$$

The above equation reflects the fact that in the process of the incremental shear band propagation by $\Delta l$, the segment $\Delta l \times h$ at the front of the sliding layer is being deformed from zero strain to $\varepsilon_{l}$, resulting in its shortening $\Delta \delta=\varepsilon_{l} \Delta l$, which causes the corresponding downward displacement of the entire layer.

Velocity of the sliding layer is then given by

$v=\frac{\Delta \delta}{\Delta t}=\varepsilon_{l} \frac{\Delta l}{\Delta t}=\varepsilon_{l} i$

where $i=\Delta l / \Delta t$ is the velocity of the shear band propagation.

The corresponding work increments are then given by the following expressions:

$\Delta W_{e}=\tau_{g} l \varepsilon_{l} \Delta l+p_{a} h \varepsilon_{l} \Delta l$

is the increment of the external work due to the work of gravity on the moving layer and of the active pressure at the failure scar on the displacements induced by the incremental shear band propagation;

$\Delta W_{i}=\Delta l h \int_{0}^{\varepsilon_{l}} \sigma_{x} d \varepsilon_{x}$

is the internal work of the normal stress acting parallel to the slope surface on the change of sub-horizontal strains in the layer above the shear band increment;

$\Delta D_{l}=\tau_{r} l \varepsilon_{l} \Delta l$

is the dissipated plastic work of the residual shear strength along the failure surface on the displacements induced by the incremental shear band propagation;

$\Delta D_{\omega}=\Delta l \int_{0}^{\delta_{r}}\left(\tau-\tau_{r}\right) d \delta=I \Delta l$

is the plastic work required to overcome the peak shear resistance at the tip of the band, i.e. the softening in the process zone, where

$I=\int_{0}^{\delta_{r}}\left(\tau-\tau_{r}\right) d \delta$ 
Equations (6)-(10) do not differ from those derived for the static analysis of the shear band propagation [12]. The following two energy terms, however, are specific for the dynamic analysis. The first term

$$
\Delta D_{\mu}=\mu v l \varepsilon_{l} \Delta l
$$

is the dissipated energy due to the viscous resistance of water proportional to the velocity of the slide on the displacements induced by the incremental shear band propagation. Here $\mu$ is the coefficient of proportionality that scales with the viscosity of water, $\mu_{w}$. The second term

$$
\Delta K=v \Delta(m v)=v \Delta(\rho h l v)=\rho h l v \Delta v+\rho h v^{2} \Delta l
$$

is the change in the kinetic energy of the sliding layer induced by the incremental shear band propagation. The change in kinetic energy is defined as a product of velocity and the increment of momentum, and for the bodies with the changing mass it has two components: due to increasing velocity and mass, respectively. The mass of the sliding layer increases proportionally to the increasing length of the shear band.

Substituting these equations into the energy balance and dividing each term by the time increment $\Delta t$, gives after certain manipulations

$$
\begin{aligned}
& {\left[\left(\tau_{g}-\tau_{r}\right) l+p_{a} h-\mu v l-\rho h l \dot{v}-\rho h \dot{l} v\right] \varepsilon_{l}} \\
& -h \int_{0}^{\varepsilon_{l}} \sigma_{x} d \varepsilon_{x}=I
\end{aligned}
$$

where from Fig. 2 (the dashed line corresponding to a linear approximation of the shear strength diagram):

$I=\int_{0}^{\delta_{r}}\left(\tau-\tau_{r}\right) d \delta=\frac{1}{2}\left(\tau_{p}-\tau_{r}\right) \delta_{m}$

The term in the square brackets in Eq. (13) can be recognised from Eq. (2), leading to

$\bar{\sigma}_{l} \varepsilon_{l}-\int_{0}^{\varepsilon_{l}} \bar{\sigma}_{x} d \varepsilon_{x}=\frac{I}{h}$

\subsection{Differential equation of the shear band propagation}

The left side of the Eq. (15) is equal to the complimentary strain energy:

$\bar{\sigma}_{l} \varepsilon_{l}-\int_{0}^{\varepsilon_{l}} \bar{\sigma}_{x} d \varepsilon_{x}=\int_{p_{0}}^{\bar{\sigma}_{l}} \varepsilon_{x} d \bar{\sigma}_{x}$

The average linear strain $\varepsilon_{x}$ can be related to the average normal stress $\bar{\sigma}_{x}$ in the layer along the shear band:

$\varepsilon_{x}=\frac{\bar{\sigma}_{x}-p_{0}}{E}$
Equations (17) can be then substituted into (16), integrated, and the result substituted into (15):

$\bar{\sigma}_{l} \varepsilon_{l}-\int_{0}^{\varepsilon_{l}} \bar{\sigma}_{x} d \varepsilon_{x}=\frac{\left(\bar{\sigma}_{l}-p_{0}\right)^{2}}{2 E}=\frac{I}{h}$

This gives

$\bar{\sigma}_{l}=p_{0}+\sqrt{\frac{2 I E}{h}}, \quad \varepsilon_{l}=\frac{\bar{\sigma}_{l}-p_{0}}{E}=\sqrt{\frac{2 I}{h E}}$

i.e., the shear band propagates at the constant normal lateral stress in the sliding layer above the band tip.

Equation of motion (2) can be then rewritten as:

$\rho h l \dot{v}+\rho h \dot{l v}+\mu v l-\left(\tau_{g}-\tau_{r}\right)\left(l-l_{c r}\right)=0$

where

$l_{c r}=\frac{h \bar{\sigma}_{l}-p_{a} h}{\tau_{g}-\tau_{r}}=\frac{\sqrt{2 I E h}-\left(p_{a}-p_{0}\right) h}{\tau_{g}-\tau_{r}}$

is the critical length of the initial shear band beyond which it starts propagating. Substitution of the Eq. (5) into (20) gives the following non-linear second order differential equation:

$$
\left(y+l_{c r}\right) \ddot{y}+(\dot{y})^{2}+a\left(y+l_{c r}\right) \dot{y}-b y=0
$$

where

$y=l-l_{c r}$

$a=\frac{\mu}{\rho h}, \quad b=\frac{\left(\tau_{g}-\tau_{r}\right)}{\varepsilon_{l} \rho h}=\frac{\left(\tau_{g}-\tau_{r}\right)}{\rho h} \sqrt{\frac{h E}{2 I}}$

with initial conditions:

$y(0)=\dot{y}(0)=0$

2.5 Simplified solution for the velocity of the shear band propagation

Equation (22) can be solved numerically. However, for large lengths of the shear band $y \gg l_{c r}$ and zero viscosity $(a=0$ for sub-aerial slides), it can be simplified as

$y \ddot{y}+(\dot{y})^{2}-b y=0$

and solved with initial conditions (25) in the closed form:

$y=\frac{b}{6} t^{2}$

Therefore,

$l=y+l_{c r}=\frac{b}{6} t^{2}+l_{c r}, \quad i=\dot{y}=\frac{b}{3} t$

and dependency of the landslide velocity on the shear band length is given by

$v=\varepsilon_{l} i=\varepsilon_{l} \sqrt{\frac{2 b}{3}} \sqrt{l-l_{c r}}$ 
Finally, substituting (19) and (24) into (29) results in

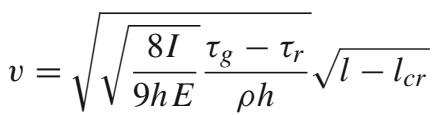

2.6 Limiting condition for the shear band propagation velocity

Approximations (28)-(30) are, strictly speaking, only valid for sub-aerial landslides. For submarine landslides, viscosity cannot be neglected $(a \neq 0)$ and another approximation has to be made. Introducing dimensionless length and time

$Y=y / l_{c r}, T=a t$

into Eq. (22) and dividing both parts by $Y+1$, gives

$\ddot{Y}+\frac{(\dot{Y})^{2}}{Y+1}+\dot{Y}-c \frac{Y}{Y+1}=0, \quad$ where $c=\frac{b}{a^{2} l_{c r}}$

We are looking for a limiting condition for the shear band propagation velocity. If for large $Y \gg 1$ velocity stabilizes, the second term in the above equation becomes small and the forth term approaches $c$, leading to

$\ddot{Y}+\dot{Y}-c=0$

which can also be solved in closed form with initial conditions (25). This gives $\dot{Y}=c\left(1-e^{-T}\right)$ or

$\dot{y}=\frac{b}{a}\left(1-e^{-a t}\right)$

which confirms that the shear band velocity cannot grow infinitely and stabilizes at larger $y$, limiting the initial landslide velocity to the maximum value of

$v=\varepsilon_{l} i=\varepsilon_{l} \frac{b}{a}=\frac{\tau_{g}-\tau_{r}}{\mu}$

The above relationship is obtained by substituting $a, b$ and $\varepsilon_{l}$ from Eqs. (19) and (24).

Note that the shear band propagation velocity is not limited by the elastic wave velocity and, therefore, theoretically, the shear band (or crack) growth can be supersonic [19] in our formulation. This situation arises because elastic wave propagations in the sliding body has been ignored and one-dimensional description of the deformations at the front, $x=l$, of the thin sliding layer has been employed. This is somewhat analogous to cases in fracture mechanics when the loading is applied directly at the crack tip and does not require energy delivered by the means of elastic waves $[20,21]$.

\section{Parametric study}

Numerical solution of the Eq. (22), and in particular its analytical approximation (30) provide an opportunity to study effects of the landslide geometry and soil properties on the initial post-failure landslide velocity, i.e, at the moment when the sliding layer separates from the underlying sediment. This velocity at failure, referred in the literature as initial landslide velocity is an important input parameter for subsequent hydrodynamic processes such as possible generation of a tsunami or a deposit of turbidities following the landslide.

\subsection{Soil properties}

Coefficients of Eqs. (21), (22) and (30) include terms, which have to be expressed via the slide geometry and soil properties. Assumptions with respect to these relationships are summarized in this section.

The gravitational shear stress is calculated as in the static case [13]

$\tau_{g}=\gamma \cdot h \cdot \sin \alpha$

where $\gamma$ is the total unit weight of soil. In undrained saturated conditions, where $\gamma^{\prime}=\gamma-\gamma_{w}\left(\gamma_{w}\right.$ denotes the unit weight of water), the peak undrained shear strength of clay can be estimated using the formulation

$\tau_{p}=s_{u}=k\left(\gamma-\gamma_{w}\right) h$

where $k$ is a factor relating the undrained shear strength to the effective stress normal to the failure plane.

In order to estimate the largest possible landslide velocity at failure, it will be assumed that the development of pore water pressures causes the residual shear strength to vanish:

$\tau_{r}=0$

e.g., as a result of the flow (static) liquefaction [22-24]. The tension crack at the top of the sliding layer is assumed to be filled with water, acting as active pressure onto the moving layer

$p_{a}=\gamma_{w} \frac{h}{2}$

while the initial total sub horizontal stress is

$p_{0}=K_{0}\left(\gamma-\gamma_{w}\right) \frac{h}{2}+\gamma_{w} \frac{h}{2}$

where $K_{0}$ is the earth pressure coefficient at rest.

In sedimentary soils, the increase of stiffness with depth can be roughly assessed from the following empirical relationship:

$E(h)=E_{0} \cdot \sqrt{\frac{h}{h_{0}}}$

where $E_{0}$ is the deformation modulus of soil at the depth $h_{0}$.

Finally, substitution of Eqs. (37) and (38) into the expression of specific work dissipated within the process zone (14) gives 
$I=\frac{1}{2} k\left(\gamma-\gamma_{w}\right) h \delta_{m}$

\subsection{Velocity of shear band propagation}

Now all the coefficients of the differential Eq. (22) and its solution (30) can be expressed via the slide geometry and soil parameters. Substitution of Eqs. (36-42) into Eq. (21) gives a formula for the critical shear band length, such that if the initial weak zone exceeds this length, the propagation of the shear band becomes catastrophic:

$l_{c r}=\frac{h \sqrt{\sqrt{\frac{h}{h_{0}}} E_{0} \cdot k\left(\gamma-\gamma_{w}\right) \delta_{m}}+K_{0}\left(\gamma-\gamma_{w}\right) \frac{h^{2}}{2}}{k\left(\gamma-\gamma_{w}\right) h}$

which can be reduced to

$l_{c r}=\sqrt{\frac{E_{0} \delta_{m}}{k\left(\gamma-\gamma_{w}\right)}} \sqrt[4]{\frac{h}{h_{0}}}+\frac{K_{0} h}{2 k}$

The parameters in the differential Eq. (22) are then given by $y=l-\sqrt{\frac{E_{0} \delta_{m}}{k\left(\gamma-\gamma_{w}\right)}} \sqrt[4]{\frac{h}{h_{0}}}-\frac{K_{0} h}{2 k} ; \quad a=\frac{\mu}{\rho h} ;$

$b=g \sin \alpha \sqrt{\frac{E_{0} \cdot \sqrt{\frac{h}{h_{0}}}}{k\left(\gamma-\gamma_{w}\right) \delta_{m}}}$

where $g=\frac{\gamma}{\rho}=9.81 \frac{\mathrm{m}}{\mathrm{s}^{2}} \approx 10 \frac{\mathrm{m}}{\mathrm{s}^{2}}$ is the gravity acceleration.

Substituting (36)-(44) into Eq. (30), results in the postfailure landslide velocity as a function of true soil parameters and the landslide size:

$v=\sqrt{\sqrt{\frac{4 k\left(\gamma-\gamma_{w}\right) \delta_{m}}{9 E_{0} \cdot \sqrt{\frac{h}{h_{0}}}}} \frac{\gamma \cdot \sin \alpha}{\rho}\left(l-\sqrt{\frac{E_{0} \delta_{m}}{k\left(\gamma-\gamma_{w}\right)}} \sqrt[4]{\frac{h}{h_{0}}-\frac{K_{0} h}{2 k}}\right)}$

\subsection{Effects of the viscosity of water}

In this section, the effect of the viscosity of water on slide velocity is analyzed. Because the analytical approximations (30) and (46) were achieved by neglecting the coefficient of proportionality $\mu$ that scales with the viscosity of water $\mu_{w}$, finite differences numerical integration of Eq. (22) with initial conditions (25) and parameters (45) have been used and the results have been compared with the analytical approximation (46). Two different landslide geometries have been considered: a shallow long slope (slope 1) and a deeper rather short slope (slope 2). Geometries are shown in Table 1.

Soil parameters have been chosen for a normally consolidated clay: $\gamma=20 \mathrm{kN} / \mathrm{m}^{3} ; K_{0}=0.5 ; k=0.25$;
Table 1 Geometric parameters of the two slopes

\begin{tabular}{lll}
\hline Parameter & Slope 1 & Slope 2 \\
\hline Slope length $L(\mathrm{~km})$ & 150 & 4.5 \\
Depth of failure surface $h(\mathrm{~m})$ & 114 & 600 \\
Slope inclination $\alpha\left(^{\circ}\right)$ & 0.5 & 12
\end{tabular}
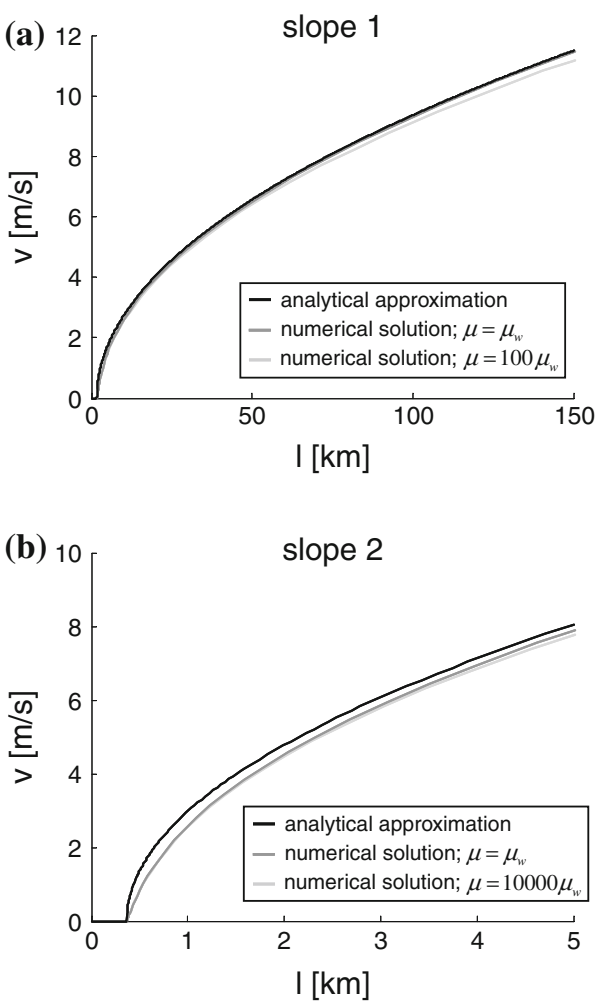

Fig. 4 Comparison of numerical and analytical solutions for two geometries: a slope 1 ; b slope 2

$\delta_{m}=0.1 \mathrm{~m}$. The stiffness curve is calibrated assuming the elasto-plastic stiffness in loading to be $E_{0}=1,000 \mathrm{kPa}$ at the depth of $h_{0}=100 \mathrm{~m}$.

The density of water is $\gamma_{w}=10 \mathrm{kN} / \mathrm{m}^{3}$ and its dynamic viscosity $\mu_{w}=0.001 \frac{\mathrm{Pa} \cdot \mathrm{s}}{\mathrm{m}}$.

Results of the comparison are presented in Fig. 4a and b, for the slopes 1 and 2, respectively. It follows, that for both geometries the difference between the numerical solution and its analytical approximation becomes negligibly small, when the shear band length reaches the failure length $l=L$ and at this moment the sliding layer separates from the underlying sediment. In the vicinity of the critical length, the approximation limits the velocity from above, mainly due to the non-zero acceleration at $l=l_{c r}$. Very soon, however, accelerations in both solutions become very close.

Exact determination of the coefficient of proportionality $\mu$ requires a solution of the corresponding hydrodynamic problem, which is beyond the scope of this paper. The parametric 
study of the range of these coefficients, however, indicates that for a rather broad range of coefficients $\mu$ (namely, $\mu=$ $\left(10^{0}-10^{2}\right) \times \mu_{w}$ for slope 1 and $\mu=\left(10^{0}-10^{4}\right) \times \mu_{w}$ for slope 2 ), the analytical formula (46) produces a reasonable approximation of the numerical solution (Fig. 4).

As is seen, within the adopted assumptions, the water does not have a significant effect on the shear band propagation.

\subsection{Parametric and sensitivity study}

Because the comparison between numerical solution and its analytical approximation has shown a good agreement at larger $l / L$ ratios, the sensitivity study on different geometric parameters can be performed using the analytical closed form solution. Substitution of the soil parameter values for normally consolidated clays presented in the previous section into Eqs. (45) and (46) gives formulas for the critical length

$l_{c r}=\frac{\sqrt[4]{h}+h / 2}{4 \cdot \sin \alpha}$

and the initial landslide velocity

$v=\sqrt{\frac{\sin \alpha}{3 \cdot \sqrt[4]{h}} \cdot L-\frac{\sqrt[4]{h^{3}}}{24}-\frac{1}{12}}$

which are the functions of the slide geometry only. Using Eq. (48), the effect of the landslide inclination $\alpha$ on the initial landslide velocity is investigated in Fig. 5a for a constant thickness of the sliding layer $h=100 \mathrm{~m}$. The effect of the thickness of the sliding layer on the initial landslide velocity is investigated in Fig. 5b for a constant landslide inclination of $\alpha=2^{\circ}$. Results are shown in a semi-logarithmic scale.

As is seen in Fig. 5a, the increased landslide inclination leads (for the same length at failure) to a drastic increase in the initial velocity, mainly, because the critical length for a steeper slide is shorter and it has more time to accelerate.

From Fig. $5 \mathrm{~b}$ it can be concluded, that the increased landslide depth leads (for the same length at failure) to a decrease in the initial velocity, mainly, because the critical length for a deeper slide is longer and it has less time to accelerate, even though its initial acceleration is higher.

\section{Initial velocities of some historic and recent tsunamigenic landslides}

\subsection{Background}

In the recent years, a number of attempts have been undertaken in the literature to simulate numerically tsunami events, triggered by submarine landslides [e.g., 9,25]. However, only few of them have been able to deliver an explanation for the
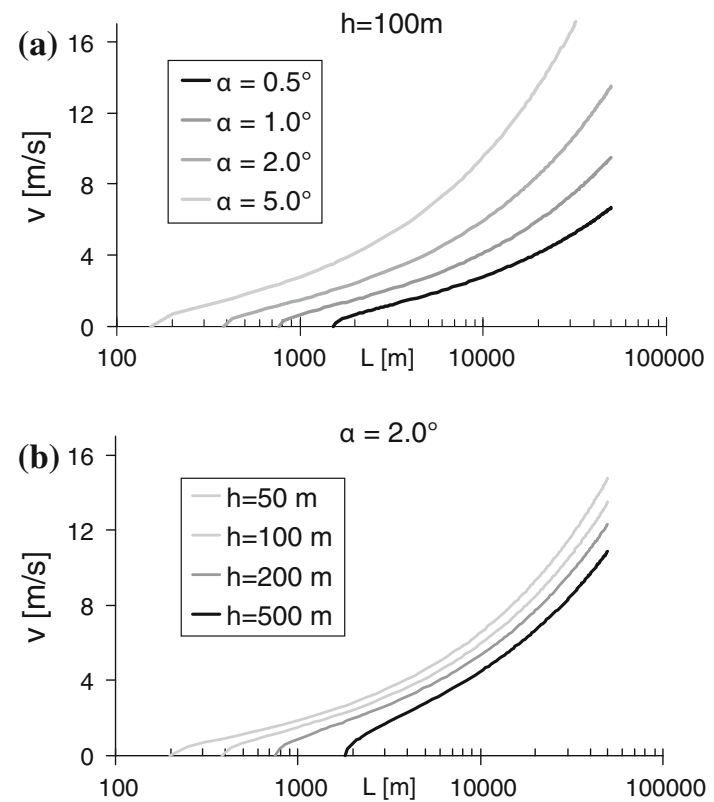

Fig. 5 Results of parametric studies: a sensitivity to changes in the slope inclination; $\mathbf{b}$ dependency on the thickness of the sliding layer

trigger source to the full extent. Most of them underestimate the tsunami wave height, indicating a necessity to account for some kind of the initial post-failure landslide velocity. The approach proposed in this paper allows for estimation of the largest possible initial velocity of a landslide at failure. But can it explain the larger tsunami wave heights? It can, provided the following two conditions are satisfied:

- Initial velocity makes a non-negligible contribution to increase the maximum landslide velocity;

- This increased maximum landslide velocity leads to a significant increase in tsunami wave height.

In this section the first condition is validated using example of five historic and recent tsunamigenic landslides, while the second condition will be assessed in the following section 5 .

\subsection{Storegga slides}

\subsubsection{Description}

The Storegga slides, situated on the continental slope off the western coast of Norway, are among the largest and best-studied submarine landslides in the world [26-28]. It is recognized that three separate landslide events occurred in the area. The first slide (Fig. 6) occurred about 30,000-50,000 years before present involving a volume of $3,880 \mathrm{~km}^{3}$, the average thickness of $114 \mathrm{~m}$ and a run-out distance of $350-400 \mathrm{~km}$ from the headwall [26], during which the altitude of the center of gravity decreased by roughly $1,500 \mathrm{~m}$. According to the 
Fig. 6 First Storegga Slide (after [26])

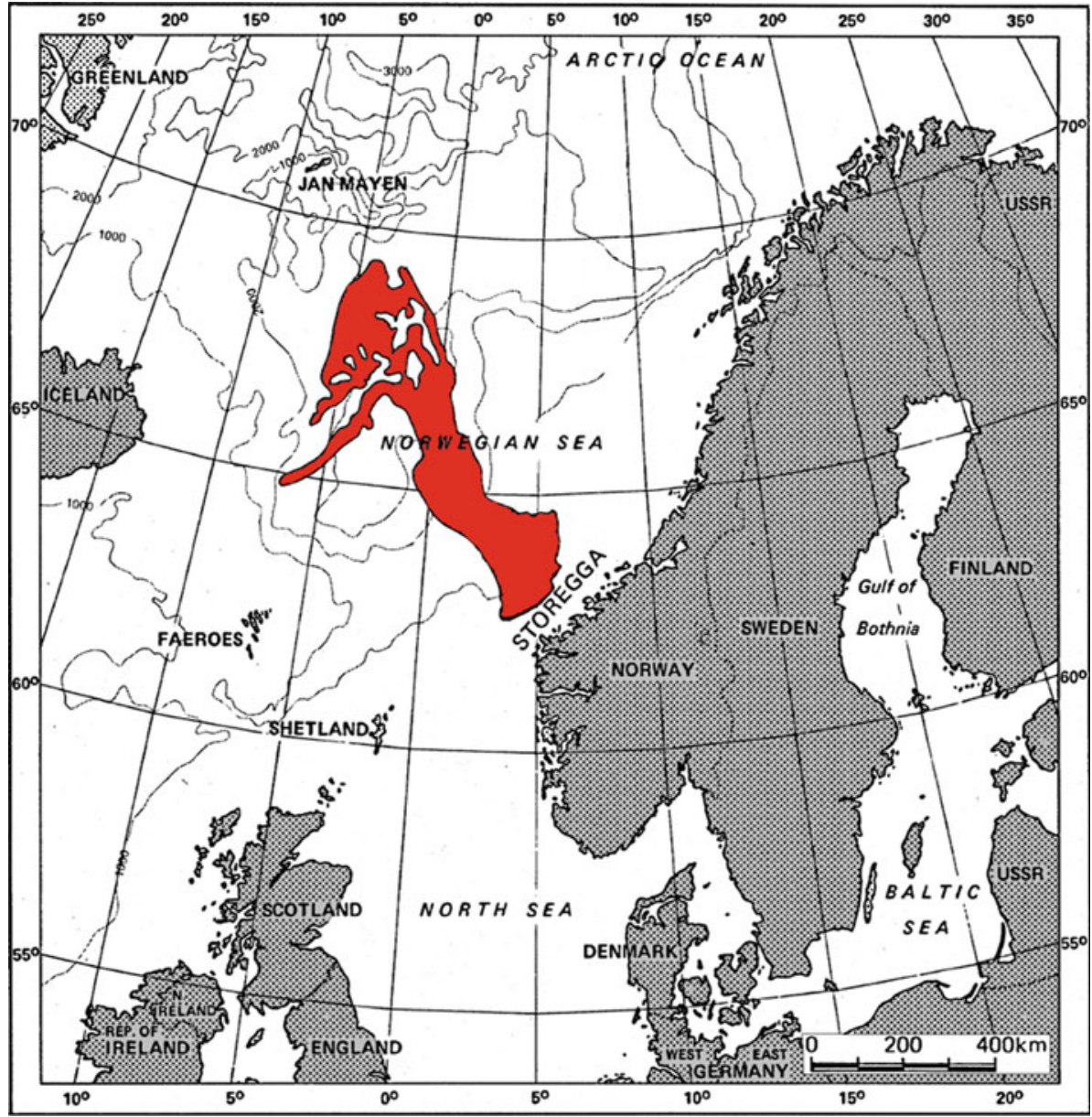

geological data, this landslide generated a tsunami wave with a height of 10-12 $\mathrm{m}$ on the coast of Norway; on the Shetland Island it was higher than $20 \mathrm{~m}$ [10]. The average water depth of the slide before the failure was about $1,500 \mathrm{~m}$.

The second slide occurred about 8,200 years ago. It has been found that the second Storegga slide consisted of one giant slide, with a volume of about $3,100 \mathrm{~km}^{3}$ and a runout of about $750 \mathrm{~km}$, followed by a multitude of smaller events. The average thickness was about $144 \mathrm{~m}$, and the height of a tsunami wave generated was of the same order of magnitude as for the First slide. The third event was limited to the upper part of the second slide scar and has not been considered here. Numerous numerical simulations of the tsunami wave heights for the first and second Storegga slides [8,10,29$31]$ indicated that rather high maximum velocities of up to $35-50 \mathrm{~m} / \mathrm{s}$ are required to get a correct correlation to the runout distances. Such high velocities are difficult to explain without accounting for some kind of the initial post-failure landslide velocity.

\subsubsection{Assumptions}

Parameters describing the geometries of the Storegga slides have been found from Refs. [8,10,26]. The total unit weight of soil has been chosen as $\gamma=17 \mathrm{kN} / \mathrm{m}^{3}$, peak strength has been estimated using $\tau_{p}=0.25 \sigma_{v^{\prime}}$, i.e. $k=0.25$ in Eq. (37). The material stiffness has been calculated using the expression from Eq. (41), with the stiffness curve calibrated assuming the elasto-plastic stiffness in loading to be $E_{0}=1,000 \mathrm{kPa}$ at the depth of $h_{0}=100 \mathrm{~m}$. Furthermore, a global inclination angle of $\alpha=0.5^{\circ}$ has been assumed. Earth pressure coefficient at rest was assumed to be $K_{0}=0.5$, the relative displacement to reach residual shear strength $\delta_{m}=$ $0.1 \mathrm{~m}$.

\subsubsection{Results}

With the obtained information and using the adopted assumptions from above, initial landslide velocities has been 
Fig. 7 Seafloor image of Goleta Slide in Santa Barbara Channel [32]. Marked area: Western Goleta Slide

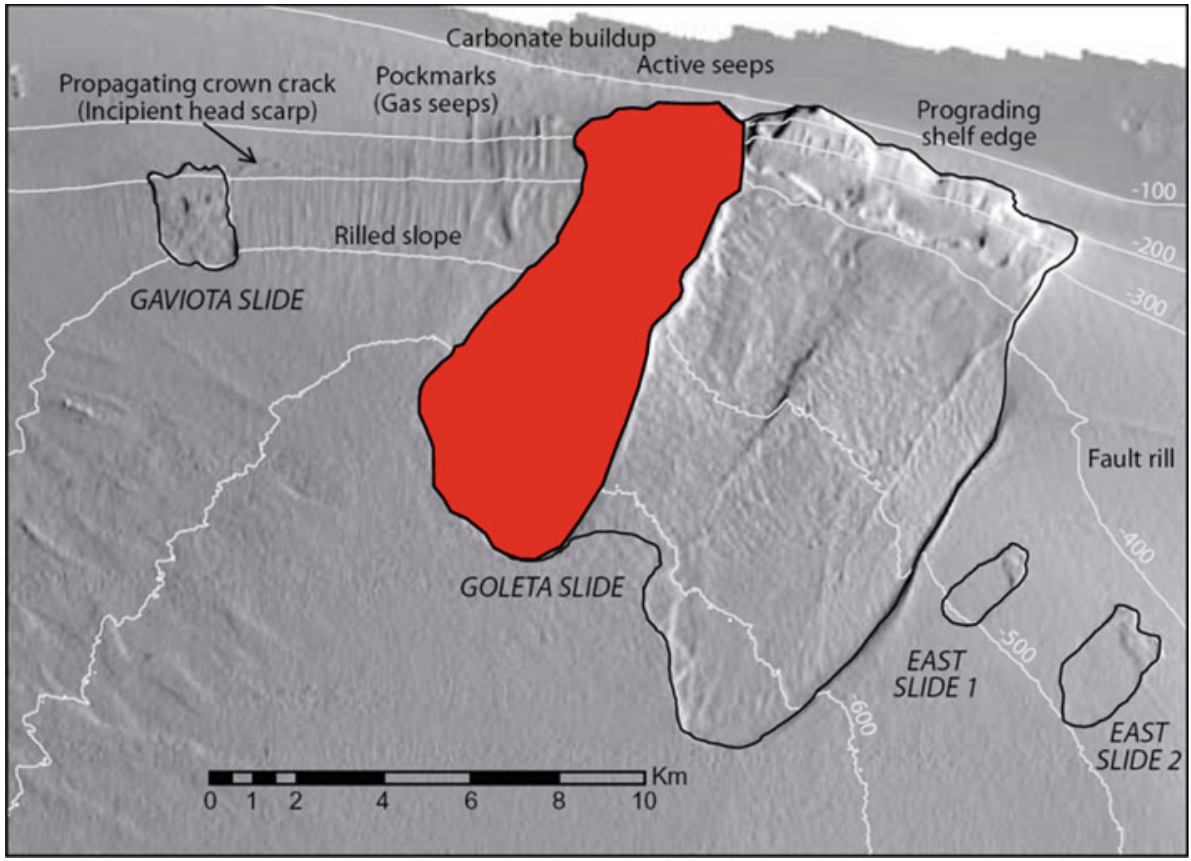

calculated to be $10.7 \mathrm{~m} / \mathrm{s}$ for the first and $10.2 \mathrm{~m} / \mathrm{s}$ for the second Storegga slide, respectively. Considering that maximum velocities required to explain the observed tsunami wave heights are $50 \mathrm{~m} / \mathrm{s}$ for the first and $35 \mathrm{~m} / \mathrm{s}$ for the second Storegga slide, respectively, the obtained initial velocities provide a non-negligible contribution.

\subsection{Western Goleta slide}

\subsubsection{Description}

Goleta Slide is situated near Coal Oil Point off the shelf edge in the Santa Barbara Basin in California (Fig. 7). It consists of three major slides (lobes) situated beneath each other. Intense detailed measurements using bathymetry, seismic reflection and remote operated vehicles (ROV) [32] allowed determination of the geometry of the slide. The compound has a total length of $14.6 \mathrm{~km}$, a width of $10.5 \mathrm{~km}$. Because it is unlikely that the entire slide failed at once, for an assessment of the presented theory only the western part is considered. The western slide had a length at failure of $6.33 \mathrm{~km}$, average thickness of $39 \mathrm{~m}$ and is located at the average water depth of $455 \mathrm{~m}$. Average inclination of the slide was $6.6^{\circ}$. From oxygen isotope stratigraphy the age of the slide has been estimated to be about 5,500years [33] Landslide analysis $[29,34]$ produced a maximum landslide velocity of $22.8 \mathrm{~m} / \mathrm{s}$ and a simulated wave height of maximum $10 \mathrm{~m}$ [32].

\subsubsection{Assumptions}

Parameters for the Goleta slide have been taken from Refs. [29,32-34]. The unit weight of soil has been chosen as $\gamma=18 \mathrm{kN} / \mathrm{m}^{3}$, peak strength has been estimated using $\tau_{p}=0.25 \sigma_{v}^{\prime}$. The material stiffness has been calculated using the expression from Eq. (41), with the stiffness curve calibrated assuming the elasto-plastic stiffness in loading to be $E_{0}=1,000 \mathrm{kPa}$ at the depth of $h_{0}=100 \mathrm{~m}$. Earth pressure coefficient at rest was again assumed to be $K_{0}=0.5$, the relative displacement to reach residual shear strength $\delta_{m}=0.1 \mathrm{~m}$.

\subsubsection{Results}

From the geometry, using the assumptions provided, an initial landslide velocity has been calculated to $9.3 \mathrm{~m} / \mathrm{s}$. The maximum velocities required to explain the observed tsunami wave heights was estimated at $22.8 \mathrm{~m} / \mathrm{s}$, which indicates that the obtained initial velocity provides here even more significant contribution than for the Storegga slides.

\subsection{Slides in Lake Lucerne}

\subsubsection{Description}

The Weggis and Chrütztrichter Slides located in Lake Lucerne (Fig. 8) occurred after an earthquake in the year 1601 and triggered a tsunami wave, with a height up to $4 \mathrm{~m}$ [35]. Field investigations [36,37] using bathymetry and core drillings in the bed of the lake allowed for estimation of the volume $\left(8.5 \times 10^{6} \mathrm{~m}^{3}\right.$ and $\left.0.18 \times 10^{6} \mathrm{~m}^{3}\right)$ and an average thickness $(3.75$ and $5.5 \mathrm{~m}$ ) of the two slides, respectively. The average run-out distance of the Weggis slide was in the range of $1,500 \mathrm{~m}$, loosing approximately $50 \mathrm{~m}$ in average altitude. Chrütztrichter slide had a run-out distance of 
Fig. 8 Bathymetric map of a part of Lake Lucerne with outlines of the Weggis and Chrütztrichter Slides. Dark grey indicates erosional, light grey depositional zones. Contour interval is $10 \mathrm{~m}$ (after $[36,37])$

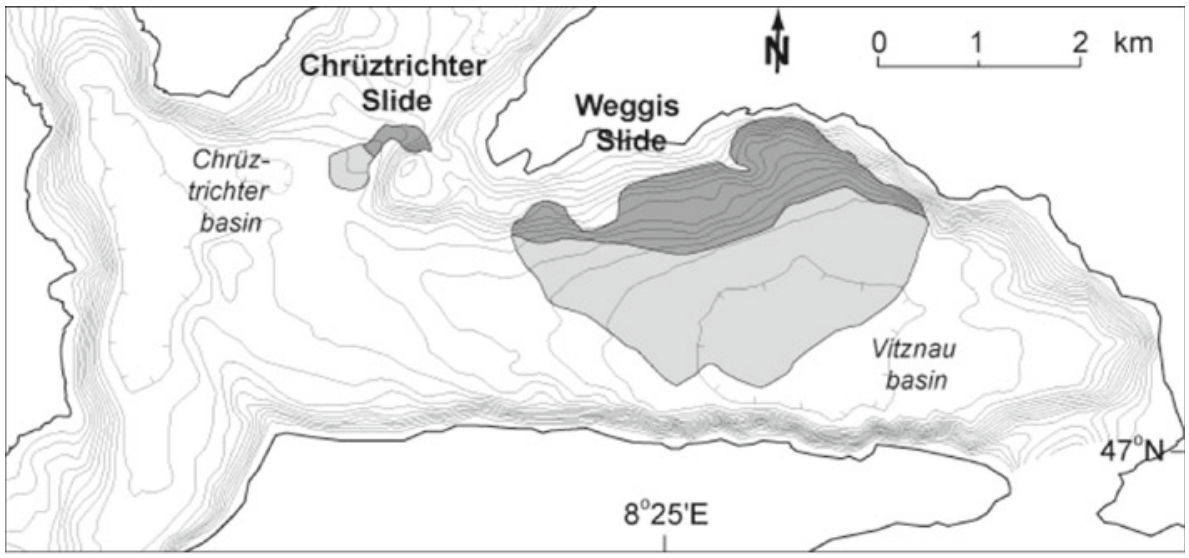

about $600-800 \mathrm{~m}$. The average water depths at Weggis and Chrütztrichter slides are roughly 100 and $90 \mathrm{~m}$, respectively.

In order to make an assessment of the maximum velocity of the slides in Lake Lucerne, simplified assessment of the maximum landslide velocity can be calculated according to [29]

$v_{\text {max }}=\sqrt{g H} \sqrt{\frac{L \sin \alpha}{H} \frac{\pi(\rho-1)}{2 C_{d}}\left(1-\frac{\tan \varphi}{\tan \alpha}\right)}$

where $H$ denotes the average water depth above the sliding body and $C_{d}$ is the global hydrodynamic drag coefficient, $L$ is the length of the slide, $\rho$ is the material density and $\varphi$ is the friction angle below the slide.

In order to get an upper bound of the maximum landslide velocity Eq. (49) can be rewritten, assuming zero friction below the slide $\varphi=0$ and $C_{d}=1.0$ to

$v_{\max }=\sqrt{\frac{L \sin \alpha}{2} \pi\left(\gamma-\gamma_{w}\right)}$

From Eq. (50) obtained maximum velocities are for the Weggis slide $28.5 \mathrm{~m} / \mathrm{s}$ and for the Chrütztrichter slide $19.7 \mathrm{~m} / \mathrm{s}$.

\subsubsection{Assumptions}

For the Weggis and Chrütztrichter slides, the peak strength has been back-calculated from the static stability analysis. It has been found that for the Weggis slide the shear strength can be estimated with $\tau_{p}=0.3-0.7 \sigma_{v}$, depending on the chosen cross-section, with inclinations of $\alpha=5-15^{\circ}$. For the Chrütztrichter slide, with an inclination of approximately $12^{\circ}$, the shear stress can be estimated using $\tau_{p}=0.56 \sigma_{v}^{\prime}$. Soil unit weight has been taken from $[36,37]$ as $16 \mathrm{kN} / \mathrm{m}^{3}$. Like in previous cases, earth pressure coefficient at rest was assumed to be $K_{0}=0.5$, the relative displacement to reach residual shear strength $\delta_{m}=0.1 \mathrm{~m}$.

\subsubsection{Results}

For the Weggis slide, the initial landslide velocities has been calculated to be within the range of $4.2-8.9 \mathrm{~m} / \mathrm{s}$, for the Chrütztrichter slide about $3.2 \mathrm{~m} / \mathrm{s}$. The maximum velocities required to explain the observed tsunami wave heights were estimated for the Weggis slide at $28.5 \mathrm{~m} / \mathrm{s}$ and for the Chrütztrichter slide at $19.7 \mathrm{~m} / \mathrm{s}$. Apparently, the initial velocity of the two lake slides does not contribute to the maximum velocity as much as by the Storegga and Goletta slides.

\subsection{Summary of initial velocity calculations}

The summary of the landslide parameters and the corresponding calculated initial velocity is shown in Table 2.

As is seen, the initial velocities for these very different landslides lie in a rather narrow range between 3.2 and $10.7 \mathrm{~m} / \mathrm{s}$. These are non-negligible velocities, when compared to the maximum velocities ranging $19.7-50 \mathrm{~m} / \mathrm{s}$, and they may have contributed to these high maximum values. Unfortunately, this does not necessarily mean that they are sufficient to affect the tsunami wave height significantly.

\section{Dependency of tsunami wave height on landslide velocity}

\subsection{Background}

The quantitative assessment of the effect of the initial velocity on the tsunami wave height of each particular landslide can be only given on the basis of numerical hydrodynamic analysis of individual cases, which is outside the scope of this paper. Some interesting qualitative observations, however, can be made based on the following considerations.

Tsunami wave height generated by an underwater landslide can be in general related to hydrodynamic parameters of the motion of the landslide, which is modeled (in the first 
Table 2 Summary of calculated initial slide velocities for investigated landslides

\begin{tabular}{llllllll}
\hline Landslide & $L(\mathrm{~km})$ & $h(\mathrm{~m})$ & $\alpha\left(^{\circ}\right)$ & $\gamma\left(\mathrm{kN} / \mathrm{m}^{3}\right)$ & $\tau_{p}(\mathrm{kPa})$ & $\begin{array}{l}\text { Initial } \\
\text { velocity }(\mathrm{m} / \mathrm{s})\end{array}$ & $\begin{array}{l}\text { Estimated maximum } \\
\text { velocity }(\mathrm{m} / \mathrm{s})\end{array}$ \\
\hline Storegga 1 & 150 & 114 & 0.5 & 17 & $0.25 \sigma_{v}^{\prime}$ & 10.7 & 50 \\
Storegga 2 & 150 & 144 & 0.5 & 17 & $0.25 \sigma_{v}^{\prime}$ & 10.2 & 35 \\
Goleta & 6.33 & 39 & 6.6 & 18 & $0.25 \sigma_{v}^{\prime}$ & 9.3 & 22.8 \\
Weggis & 1 & 3.75 & $5-15$ & 16 & $0.3-0.7 \sigma_{v}^{\prime}$ & $4.2-8.9$ & 28.5 \\
Chrütztrichter & 0.2 & 5.5 & $\sim 12$ & 16 & $0.56 \sigma_{v}^{\prime}$ & 3.2 & 19.7 \\
& & & & & & & \\
\hline
\end{tabular}

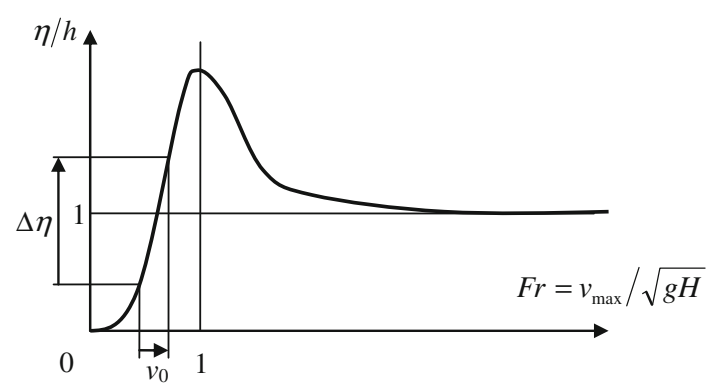

Fig. 9 Typical dependency of the tsunami height on the landslide velocity (after [38])

approximation) as a solid block [34]. In this case, wave height $\eta$ and landslide velocity $v_{\max }$ can be related via the Froude number [25]. For tsunamigenic landslides this number relates the linear long-wave velocity $c_{0}=\sqrt{g H}$ at a water depth of $H$ (where $g$ is the gravity acceleration), to the maximum landslide velocity $v_{\max }$ and is defined as

$F r=\frac{v_{\max }}{\sqrt{g H}}$

Sub-critical, critical and super-critical landslide motions are defined as $F r<1, F r=1$ and $F r>1$, respectively. Critical landslide motion produces tsunami waves several times higher than the thickness of the landslide $h$ (Fig. 9). For larger water depths, most of the landslides are going to be subcritical. In this sub-critical zone, however, effect of the initial velocity of the landslide is not uniform: as is seen from Fig. 9, for smaller Froude numbers initial velocity causes a relatively larger increase in the tsunami wave height $\Delta \eta$ than for larger Froude numbers, due to the strong nonlinearity of the $\eta(F r)$ plot. In the following this effect is discussed for the five landslides introduced in the previous section.

\subsection{Storegga slides}

For the first Storegga slide the maximum landslide velocity was estimated at about $50 \mathrm{~m} / \mathrm{s}$, for the second $35 \mathrm{~m} / \mathrm{s}$ [8]. Assuming an average water depth of the Storegga landslide of $1,500 \mathrm{~m}$ results in a tsunami wave velocity $c_{0}=\sqrt{g H}$ of about $120 \mathrm{~m} / \mathrm{s}$. Consequently, with the relatively small
Froude numbers of 0.41 and 0.29 for the first and the second Storegga slides, respectively, the corresponding initial velocities in of 10.7 and $10.2 \mathrm{~m} / \mathrm{s}$ are likely to increase the tsunami wave heights more significantly than their relative contribution to the maximum velocities.

\subsection{Western Goleta slide}

Simulation of Greene et al. [32] resulted in a maximum landslide velocity for the Goleta slide of $22.8 \mathrm{~m} / \mathrm{s}$. The wave velocity has been estimated to be $c_{0}=67 \mathrm{~m} / \mathrm{s}$, resulting in a Froude number of 0.34 , which again is in the lower part of the subcritical region (Fig. 9). Therefore, similar to Storegga slides, the initial velocity of $9.3 \mathrm{~m} / \mathrm{s}$ is likely to increase the tsunami wave heights more significantly than its relative contribution to the maximum velocity. Note, that this relative contribution for the case of Goleta landslide is also the highest one among the landslides analyzed in this paper.

\subsection{Slides in Lake Lucerne}

Maximum velocities for the Weggis slide $(28.5 \mathrm{~m} / \mathrm{s})$ and for the Chrütztrichter slide $(19.7 \mathrm{~m} / \mathrm{s})$ were obtained from Eq. (50) in the Sect. 4. Water wave velocities have been calculated for average water depth of $90-100 \mathrm{~m}$ for the Weggis and Chrütztrichter slides, resulting in $c_{0}=32 \mathrm{~m} / \mathrm{s}$ and $c_{0}=30 \mathrm{~m} / \mathrm{s}$, respectively. The Froude numbers, though still being in the subcritical zone are rather large $(0.89$ and 0.65 , respectively). Therefore, unlike Storegga and Goleta slides, the initial velocities of $4.2-8.9$ and $3.2 \mathrm{~m} / \mathrm{s}$ for the Weggis and Chrütztrichter slides, respectively, are likely to increase the tsunami wave heights less than their relative contributions to the maximum velocity, which are not high anyway.

\subsection{Summary and discussion}

The calculated Froude numbers for all the landslides are summarized in Table 3. As is seen from Table 3, the Froude numbers for all the landslides are smaller than unity; i.e. their motion appears to be subcritical. From Fig. 9 it follows, however, that different initial velocities will have a different effect 
Table 3 Summary of calculated Froude numbers for investigated landslides

\begin{tabular}{|c|c|c|c|c|c|c|}
\hline Landslide & $\begin{array}{l}\text { Average water } \\
\text { depth } H(\mathrm{~m})\end{array}$ & $\begin{array}{l}\text { Wave } \\
\text { velocity }(\mathrm{m} / \mathrm{s})\end{array}$ & $\begin{array}{l}\text { Estimated maximum } \\
\text { velocity }(\mathrm{m} / \mathrm{s})\end{array}$ & $\begin{array}{l}\text { Initial } \\
\text { velocity }(\mathrm{m} / \mathrm{s})\end{array}$ & $\begin{array}{l}\text { Froude } \\
\text { number (-) }\end{array}$ & $\begin{array}{l}\text { Tsunami wave } \\
\text { height }(\mathrm{m})\end{array}$ \\
\hline Storegga 1 & 1,500 & 122 & 50 & 10.7 & 0.41 & $10-12$ \\
\hline Storegga 2 & 1,500 & 122 & 35 & 10.2 & 0.29 & $10-12$ \\
\hline Goleta & 455 & 67 & 22.8 & 9.3 & 0.34 & 10 \\
\hline Weggis & 100 & 32 & 28.5 & $4.2-8.9$ & 0.89 & 4 \\
\hline Chrütztrichter & 90 & 30 & 19.7 & 3.2 & 0.65 & 4 \\
\hline
\end{tabular}

on the tsunami waves caused by these landslides. The largest effect is expected for the Goleta and second Storegga slides, where initial velocity is $30-40 \%$ of the maximum velocity and small Froude numbers ensure that their relative effect on the tsunami wave height will be even higher. The smallest effect is expected for the Weggis and Chrütztrichter slides, where initial velocity is only $15-25 \%$ of the maximum velocity and larger Froude numbers cause their relative effect on the tsunami wave height to be even smaller. More detailed quantitative conclusions, however, can be only made based on a proper hydrodynamic numerical analysis, in which the initial velocities from Tables 2 and 3 can be used as an input parameter.

\section{Summary and conclusions}

A stable numerical solution and its closed form approximation have been obtained for the velocity of the submarine tsunamigenic landslides at failure. The landslide mechanism is based on the phenomenon of the dynamic shear band propagation, analyzed using the energy balance approach. Inertia effects and viscous water resistance have been included into the analysis, while the propagation and reflection of the $\mathrm{P}$-waves within the sliding layer have been neglected. For a number of different landslides these velocities appeared to be of the order of magnitude of $1-10 \mathrm{~m} / \mathrm{s}$.

The shear band propagation velocity in this solution is not limited by the shear wave velocity, and for an infinite slope this velocity can become rather large. This does not represent a problem, however, because the proposed formulation does not require energy delivered to the shear band tip. In the nature, however, no infinite slopes exist and the shear band would sooner or later propagate to the surface, causing the slope failure at a finite velocity.

In a number of very different slides considered in this paper the initial velocities did not exceed the order of $10 \mathrm{~m} / \mathrm{s}$, which are, probably, the largest initial velocities that could develop in realistic environment. For subcritical slides with low Froude numbers and maximum landslide velocities this may affect significantly the tsunami wave heights and run-out distances. A proper rigorous hydrodynamic analysis, using the estimated initial velocities as an input, is required to confirm these findings.

Acknowledgments The project has been supported by Swiss National Science Foundation through Grant No. 200021-109195 and by the United States National Science Foundation Grants OCE-0242163 and CMC-0421090.

\section{References}

1. Liam Finn, W.D.: Landslide-generated tsunamis: geotechnical considerations. Pure Appl. Geophys. 160, 1879-1894 (2003)

2. Okal, E.A., Synolakis, C.E.: A theoretical comparison of tsunamis from dislocations and landslides. Pure and Appl. Geophys. 160, 2177-2188 (2003)

3. Tappin, D.R., Matsumoto, T., Watts, P., Satake, K., McMurty, G.M., Matsuyama, M., Lafoy, Y., Tsuji, Y., Kanamatsu, T., Lus, W., Iwabuchi, Y., Yeh, H., Matsumotu, Y., Nakamura, M., Mahoi, M., Hill, P., Crook, K., Anton, L., Walsh, J.P.: Sediment slump likely caused 1998 Papua New Guinea Tsunami. Eos Trans. Am. Geophys. Union 80(30), 329-344 (1999)

4. Ioualalen, M., Asavanant, J., Kaewbanjak, N., Grilli, S.T., Kirby, J.T., Watts, P.: Modeling the 26 December 2004 Indian Ocean Tsunami: case study of impact in Thailand. J. Geophys. Res. 112(C07024), 1-21 (2007)

5. Yamashita, T., Sato, R.: Generation of tsunami by a fault model. J. Phys. Earth 22, 415-440 (1974)

6. Bardet, J.-P., Synolakis, C.E., Davies, H.L., Imamura, F., Okal, E.A.: Landslide tsunamis: recent findings and research directions. Pure and Appl. Geophys. 160, 1793-1809 (2003)

7. Wright, S.G., Rathije, E.M.: Triggering mechanisms of slope instabilities and their relation to earthquakes and Tsunamis. Pure Appl. Geophys. 160, 1865-1877 (2003)

8. Harbitz, C.B.: Model simulations of tsunamis generated by the Storegga slides. Mar. Geol. 105, 1-21 (1992)

9. Murty, T.S.: Tsunami wave height dependence on landslide volume. Pure Appl. Geophys. 160, 2147-2153 (2003)

10. Bondevik, S., Løvholt, F., Harbitz, C., Mangerud, J., Dawson, A., Svendsen, J.I.: The storegga slide tsunami-comparing field observations with numerical simulations. Mar. Pet. Geol. 22, 195208 (2005)

11. Puzrin, A.M., Germanovich, L.N.: The mechanism of tsunamigenic landslides. Geomech. Test. Model. Simul. GSP 143, 421428 (2003)

12. Puzrin, A.M., Germanovich, L.N.: The growth of shear bands in the catastrophic failure of soils. Proc. Roy. Soc. Lond. A 461, 1199_ $1228(2005)$ 
13. Palmer, A.C., Rice, J.R.: The growth of slip surfaces in the progressive failure of over-consolidated clay. Proc. Roy. Soc. Lond. A 332, 527-548 (1973)

14. Rudnicky, J.W., Rice, J.R.: Conditions for the localization of deformation in pressure-sensitive dilatant materials. J. Mech. Phys. Solids 23, 371-394 (1975)

15. Saurer, E., Puzrin, A.M.: On simulation of shear band propagation in trapdoor-tests. In: Procreedings of the NUMOG X, pp. 119-123 (2007)

16. Saurer, E., Puzrin, A.M.: Energy balance approach to shear band propagation in shear-blade tests. In: Proceedings of the 12th IACMAG, pp. 1024-1031 (2008)

17. Puzrin, A.M., Germanovich, L.N., Kim, S.: Catastrophic failure of submerged slopes in normally consolidated sediments. Géotechn 54(10), 631-643 (2004)

18. Puzrin, A.M., Saurer, E., Germanovich, L.N.: Simplified dynamic solution of the shear band propagation in submerged landslides. accepted for Proc. Int. Symp. Predict. Sim. Methods for Geohaz. Mitigation, pp. 85-90 (2009)

19. Freund, L.B.: Dynamic Fracture Mechanics. pp. 584 Cambridge University Press, Cambridge (1990)

20. Winkler, S., Shockey, D.A., Curran, D.R.: Crack propagation at supersonic velocities I. Int. J. Fract. Mech. 6(2), 151-158 (1970)

21. Curran, D.R., Shockey, D.A., Winkler, S.: Crack propagation at supersonic velocities. Int. J. Fract. Mech. 6, 271-278 (1970)

22. Kramer, S.L., Bolton Seed, H.: Initiation of soil liquefaction under static loading conditions. J. Geotech. Eng. 114(4), 412-430 (1988)

23. Norris, G.M.: Advances in effective stress approach to liquefaction analysis. Phys. Mech. Soil Liquefaction. Lade, P., Ymamuro, J., (Eds.), pp. 41-52. Balkema, Rotterdam (1999)

24. Andrade, J.E.: A predictive framework for liquefaction instability. Géotechnique 59(8), 673-682 (2009)

25. Harbitz, C.B., Løvholt, F., Pedersen, G., Masson, D.G.: Mechanisms of tsunami generation by submarine landslides: a short review. Norw. J. Geol. 86, 255-264 (2006)

26. Bugge, T., Belderson, R.H., Kenyon, N.H.: The storegga slide. Phil. Trans. Roy. Soc. Lond. A 325, 357-388 (1988)
27. Haflidason, H., Sejrup, H.P., Nygard, A., Mienert, J., Bryn, P., Lien, R., Forsberg, C.F., Berg, K., Masson, D.: The Storegga slide: architecture, geometry and slide development. Mar. Geol. 213, 201234 (2004)

28. Kvalstad, T.J., Andresen, L., Forsberg, C.F., Berg, K., Bryn, P., Wangen, M.: The Storegga slide: evaluation of triggering sources and slide mechanics. Mar. Pet. Geol. 22, 245-256 (2005)

29. Grilli, S.T., Watts, P.: Tsunami generation by submarine mass failure. I: modeling, experimental validation, and sensitivity analyses. J. Waterw. Port Coast. Ocean Eng. 131(6), 283-297 (2005)

30. Grilli, S.T., Watts, P.: Tsunami generation by submarine mass failure. II: predictive Equations and case studies. J. Waterw. Port Coast. Ocean Eng. 131(6), 298-310 (2005)

31. DeBlasio, F.V., Elverhøi, A., Issler, D., Harbitz, C.B., Bryn, P., Lien, R.: On the dynamics of subaqueous clay rich gravity mass flows-the giant Storegga slide, Norway. Mar. Pet. Geol. 22, 179186 (2005)

32. Greene, H.G., Murai, L.Y., Watts, P., Maher, N.A., Fisher, M.A., Paull, C.E., Eichhubl, P.: Submarine landslides in the Santa Barbara Channel as potential tsunami sources. Nat. Haz. Earth Sys. Sci. 6, 63-88 (2006)

33. Lee, H.J., Normark, W.R., Fisher, M.A., Greene, H.G., Edwards, B.D., Locat, J.: Timing and extent of submarine landslides in Southern California. OTC 16744 (2004)

34. Watts, P.: Tsunami features of solid block underwater landslides. J. Waterw. Port Coast. Ocean Eng. 126(3), 144-152 (2000)

35. Cysat, R.: Collectanea Chronica und denkwürdige Sachen pro Chronica Lucernensi et Helveticae. In: Schmid, J. (ed.) Quellen und Forschungen zur Kulturgeschichte von Luzern und der Innerschweiz vol. I, pp. 882-888. Diebold Schilling Verlag, Luzern (1601)

36. Schnellmann, M.P.: Late quaternary mass movements in a perialpine lake. Diss. ETH No. 15533 (2004)

37. Strasser, M.: Quantifying late quaternary natural hazards in Swiss lakes. Diss. ETH No. 17285 (2008)

38. Ward, S.N.: Landslide tsunami. J. Geophys. Res. 106(B6), 11,201$11,215(2001)$ 